\title{
CHAIN OF SURVIVAL USED FOR A VICTIM OF SUDDEN CARDIAC ARREST IN A PUBLIC PLACE
}

\author{
Wojciech Telec ${ }^{1}$, Tomasz Klosiewicz ${ }^{1,2}$, Radosław Zalewski ${ }^{1}$, Ilona Skitek-Adamczak ${ }^{1}$ \\ 'Department of Medical Rescue, Chapter of Emergency Medicine, \\ Poznan University of Medical Sciences, Poznan, Poland \\ ${ }^{2}$ Polish Society of Medical Simulation, Poland
}

\begin{abstract}
The complete chain of survival is highly recomended management of sudden cardiac arrest. Although it is well known, in Poland not always works properly, because of poor availability to AED devices. We present the history of 56 years old man, who suddenly suffered from sudden cardiac arrest in public place. Thanks to rapid reaction of his family and medical staff this men recived high quality resuscitation including AED and spontaneous circulation returnem before paramedics arrived. On admission to emergency department the patient was awake, without neuroligic deficites. Miocardial infarction was diagnosed as the cause of cardiac arrest.
\end{abstract}

KEY WORDS: cardiac arrest, survivor, defibrillation, resuscitation

Disaster Emerg Med J 2017; 2(3): 135-136

\section{INTRODUCTION}

Sudden cardiac arrest (SCA) survival in Europe is dependent on the country where the incident takes place. The country with the highest survival rate for SCA is Netherlands (38.8\%) [1]. In Poland, approximately 40,000 people suffers a cardiac arrest annually, and the survival rate is not more than $10 \%[2,3]$. In about $65 \%$ of cases this is caused by ventricular fibrillation. It is widely believed that the most effective treatment for cardiac arrest is to perform early defibrillation as soon as possible [4]. An article by Claesson et al. described the use of AEDs (automated external difibrillators) prior to the arrival of EMS (emergency medical service) personnel among 6,675 patients that had an OHSCA (out-of-hospital sudden cardiac arrest) in the region of western Sweden between 2008 and 2015 [5]. They indicated that a strategy of increasing use of AEDs before the arrival of the EMS in OHSCA was associated with an increase in survival among patients found with ventricular fibrillation. This relationship is also confirmed by our own experience in the case report described below.

\section{MATERIAL AND METHODS}

On 29 May 2013, at 10.14, the Regional Dispatch Centre in Poznan received a call from the Polish Army Training Centre in Poznan concerning cardiopulmonary resuscitation being undertaken in a 56-year old man. At 10.15, an ambulance (carrying two paramedics) was dispatched. The time to arrival was 5 minutes. Upon arrival, the victim was lying on his back, being assisted by three soldiers (a doctor and two paramedics). They were a part of a welcoming ceremony for new incoming soldiers. Based on interviews, the victim suddenly lost consciousness. Although his past history is positive for cardiac problems, his family was unable to accurately determine the details regarding the diagnosis and management. The victim had undertaken a long journey to take part in the military ceremony. The man was stressed during the journey thinking about time and getting lost on the road, since this was a spontaneous and last-minute trip. The first witness to this incident was the victim's son, who immediately noticed the lack of breathing and began chest compressions. After one minute, three 
solders equipped with AEDs were on the scene. The device recommended to perform one defibrillation, then continue resuscitation, until the return of spontaneous circulation. The initial examination revealed the following: unobstructed airways; bilateral breath sounds; RR 20/min; Sp02 88\%; HR 60/min; BP 120/80 mmHg; CRT < 2 s; pale, moist and warm skin; the patient was awake and agitated, without logical contact; and GCS of 13 points. Because of the agitation, the patient received $5 \mathrm{mg}$ of diazepam IV, oxygen therapy was started, while POC blood glucose was found to be $161 \mathrm{mg} / \mathrm{dl}$. In a 12-lead ECG, the following was recorded: normal sinus rhythm with a frequency of 80 beats/min; a prolonged PR interval of (280 ms); left bundle branch block and right bundle branch block; inverted T wave in leads I, aVR, aVL, VI-V4; ST segment depression in VI-V4. Infusion of $500 \mathrm{ml}$ of normal saline was initiated. The dispatcher was asked to inform the emergency department where the patient to be transferred. The time from first medical contact to hospital arrival was 40 minutes. At the time of admission to the ED, the patient remained conscious, preserved verbal contact with amnesia while reporting shortness of breath and discomfort in the chest. On admission, an echocardiography was performed and revealed significant left ventricular dysfunction with reduced ejection fraction (approx. 35\%) and severe aortic stenosis (calcified flakes that restrict motility, maximal speed $4.4 \mathrm{~m} / \mathrm{s}$, mean pressure gradient $44 \mathrm{~mm} \mathrm{Hg}$ ). In the treatment of his heart failure, intensive drug therapy was used to provide a gradual resolution. Due to the initial poor condition and clinical features of heart failure, a decision to initiate conservative treatment was made while a coronary angiography was performed after cardiac stabilization.

\section{DISCUSSION}

The International Liaison Committee on Resuscitation (ILCOR) provides updated guidelines for resuscitation every 5 years. The sequence of events that should be performed in the event of cardiac arrest is called the chain of survival. We think that this case is interesting because all links of the chain of survival were executed. The witness correctly and immediately recognized cardiac arrest and began chest compressions. There was an instantly activated emergency medical system, while on-site medical personnel were equipped with an AED and correctly used its potential. The patient with preserved contact was transported to hospital where he was diagnosed with a heart attack and subjected to coronary angiography treatment with angioplasty. The chain consists of the following links: 1 - recognition of cardiac arrest and activation of emergency response system; 2 - early cardiopulmonary resuscitation; 3 - rapid defibrillation; and 4 - advanced life support and post-cardiac arrest care $[6,7]$. This case presents a man who was a victim of sudden cardiac arrest in public place. Public Access Defibrillators are still not common in Poland when compare to other European cities. Also the Poles' knowledge about AED is poor [8]. The quick reaction and use of the defibrillator, had helped to return spontaneous circulation to the patient before an ambulance arrived. This resulted in another life saved.

Conflict of interest: None declared.

\section{REFERENCES}

1. Atwood C, Eisenberg MS, Herlitz J, et al. Incidence of EMS-treated out-of-hospital cardiac arrest in Europe. Resuscitation. 2005; 67(1): 75-80, doi: 10.1016/j.resuscitation.2005.03.021, indexed in Pubmed: 16199289.

2. Rudner $R$, Jalowiecki $P$, Karpel $E$, et al. Survival after out-of-hospital cardiac arrests in Katowice (Poland): outcome report according to the "Utstein style". Resuscitation. 2004; 61(3): 315-325, doi: 10.1016/j. resuscitation.2004.01.020, indexed in Pubmed: 15172711.

3. Jankowski D. Out-of-hospital sudden cardiac arrest in the population of adults in Szczecin, years 2002-2003. Ann Acad Med Stetin. 2007; 53(1): 33-42, indexed in Pubmed: 18561608.

4. Kostera RW, Baubin MA, Bossaert LL, et al. European Resuscitation Council Guidelines for Resuscitation 2010 Section 2. Adult basic life support and use of automated external defibrillators. Resuscitation. 2010; 81(10): 1277-1292, doi: 10.1016/j.resuscitation.2010.08.009, indexed in Pubmed: 20956051.

5. Claesson A, Herlitz J, Svensson L, et al. Defibrillation before EMS arrival in western Sweden. Am J Emerg Med. 2017; 35(8): 1043-1048, doi: 10.1016/j.ajem.2017.02.030, indexed in Pubmed: 28238537.

6. Nolan JP, Soarb J, Zideman D, et al. European Resuscitation Council Guidelines for Resuscitation 2010 Section 9. Principles of education in resuscitation. Resuscitation. 2010; 81(10): 1219-1276, doi: 10.1016/j. resuscitation.2010.08.014, indexed in Pubmed: 20956044.

7. Gheeraert PJ, De Buyzere ML, Taeymans YM, et al. Risk factors for primary ventricular fibrillation during acute myocardial infarction: a systematic review and meta-analysis. Eur Heart J. 2006; 27(21): 2499-2510, doi: 10.1093/eurheartj/ehl218, indexed in Pubmed: 16952926.

8. Kozłowski D, Kłosiewicz T, Kowalczyk A, et al. The knowledge of public access to defibrillation in selected cities in Poland. Arch Med Sci. 2013; 9(1): 27-33, doi: 10.5114/aoms.2013.33345, indexed in Pubmed: 23515455. 